\title{
Westward propagation of barrier layer formation in the 2006-07 Rossby wave event over the tropical southwest Indian Ocean
}

\author{
J. S. Chowdary, ${ }^{1,2}$ C. Gnanaseelan, ${ }^{1}$ and S. P. Xie ${ }^{2}$ \\ Received 12 November 2008; revised 22 January 2009; accepted 27 January 2009; published 24 February 2009.
}

[1] A suite of satellite and in-situ observations are used to study ocean-atmospheric conditions over the tropical Southwest Indian Ocean (SWIO) during 2006-2007 when El Nino and an Indian Ocean dipole took place simultaneously. Argo profiles reveal a pronounced up-westward propagation of subsurface warming in the southern tropical Indian Ocean associated with Rossby waves traveling on the sloping thermocline. With the thermocline deepening by $60 \mathrm{~m}$, a thick barrier layer forms and propagates with the Rossby wave, potentially contributing to the mixed layer warming. Citation: Chowdary, J. S., C. Gnanaseelan, and S. P. Xie (2009), Westward propagation of barrier layer formation in the 2006-07 Rossby wave event over the tropical southwest Indian Ocean, Geophys. Res. Lett., 36, L04607, doi:10.1029/ 2008GL036642.

\section{Introduction}

[2] Most subsurface observations in the Indian Ocean were based exclusively on sparse measurements from ships prior to 2000. This has changed drastically for the last few years with the deployment of Array for Real-time Geostrophic Oceanography (Argo) floats [Gould et al., 2004]. A typical Argo float profiles ocean temperature and salinity once every 10 days from the surface to $2000 \mathrm{~m}$ depth. The rapid expansion in subsurface measurements is revolutionizing ocean and climate observations and research. Here we report on an Argo application of observing a major Rossby wave event over the tropical Southwest Indian Ocean (SWIO) or Seychelles-Chagos thermocline ridge (SCTR; $5^{\circ} \mathrm{S}$ to $10^{\circ} \mathrm{S}, 50^{\circ} \mathrm{E}$ to $80^{\circ} \mathrm{E}$ ) [Vialard et al., 2009; Hermes and Reason, 2008; Yokoi et al., 2008] following the 200607 El Nino.

[3] The tropical SWIO emerges as a climatically important region [Schott et al., 2009], where the thermocline shoals in response to basin-scale Ekman pumping and subsurface anomalies readily affect SST. During El Nino, atmospheric teleconnection forces downwelling Rossby waves, which propagate westward [Masumoto and Meyers, 1998] and induce SST warming in the tropical SWIO [Xie et al., 2002; Huang and Kinter, 2002]. The relative effect of El Nino and the Indian Ocean Dipole (IOD) [Saji et al., 1999] in generating downwelling Rossby waves over this region is discussed by $Y u$ et al. [2005] and Chowdary and Gnanaseelan [2007]. Rossby wave-induced SST anomalies

\footnotetext{
${ }^{1}$ Theoretical Studies Division, Indian Institute of Tropical Meteorology, Pune, India.

${ }^{2}$ International Pacific Research Center and Department of Meteorology, SOEST, University of Hawaii, Honolulu, Hawaii, USA.
}

Copyright 2009 by the American Geophysical Union. 0094-8276/09/2008GL036642\$05.00 affect atmospheric convection and tropical cyclones over the SWIO [Xie et al., 2002], rainfall anomalies over eastern South Africa [Reason and Mulenga, 1999] and the tropical western Pacific, and the subsequent Indian monsoon [Annamalai et al., 2005] especially over the western ghats of India [Izumo et al., 2008; Vecchi and Harrison, 2004]. The shallow thermocline in the SWIO helps enhance intraseasonal variability in SST [Duvel et al., 2004].

[4] While interannual Rossby waves are routinely monitored from satellite altimeters since 1992 and in SST, their vertical structure has never been systematically observed across the Indian Ocean, except on a few expendable bathythermograph (XBT) lines. A moderate El Nino took place during 2006-07. Its co-occurrence with the 2006 IOD event [Vinayachandran et al., 2007] has generated a strong downwelling Rossby wave in the Southern Tropical Indian Ocean (STIO). This is the first major STIO Rossby wave event since Argo floats have been fully deployed. The VASCO-Cirene field experiment in the tropical SWIO region during January-February 2007 [Vialard et al., 2009] observed strong warming in the thermocline and at the surface.

[5] The present study presents the first subsurface observations of ocean Rossby waves across the STIO based on Argo and XBT profiles. We show that Argo adequately captures subsurface anomalies of this downwelling Rossby wave and their westward propagation across the basin. Our analysis reveals a remarkable co-propagation in barrier layer thickness, which potentially affects the thermocline feedback on SST. In the following, Section 2 describes the data. Sections 3-4 present results from our Argo analysis, describing the ocean Rossby wave and its influences on the barrier layer. Section 5 is summary.

\section{Data}

[6] Quality controlled Argo (temperature and salinity) and XBT (temperature) profiles are obtained from http:// Www.coriolis.eu.org and optimally interpolated onto a $2^{\circ}$ by $2^{\circ}$ grid over the tropical Indian Ocean, following Barth et al. [2007]. The analysis is performed from January 2005 to May 2007 at 18 standard levels (from 10 to $1000 \mathrm{~m}$ ). The World Ocean Atlas (WOA) 2005 climatology is used as the background field, from which anomalies are defined. As most Argo floats do not report data above $10 \mathrm{~m}$, temperature at $10 \mathrm{~m}$ is considered as SST. Our Optimal Interpolation Analysis (OIA) of Argo and XBT observations compare well with the Reynolds et al. [2002] SST analysis and satellite altimeter data (Figure 1). This gives confidence to our OIA dataset since the Reynolds analysis uses much more SST measurements, both in-situ and from satellite. Our OIA vertical profiles also compare well with the TAO/ 

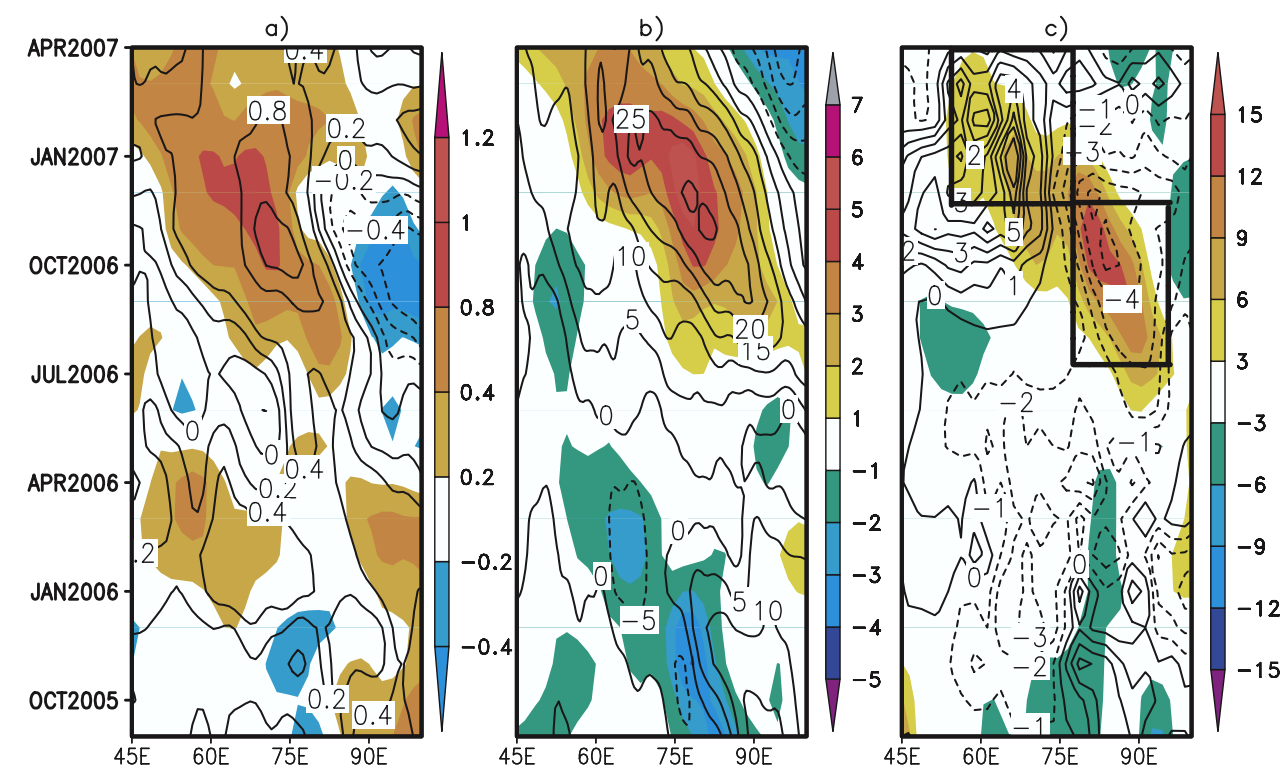

Figure 1. Time-longitude sections of anomalies at $10^{\circ} \mathrm{S}$ : (a) OIA (shaded) and Reynolds (contours in ${ }^{\circ} \mathrm{C}$ ) SST; (b) OIA subsurface temperature at $100 \mathrm{~m}$ (shaded in ${ }^{\circ} \mathrm{C}$ ) and SSH (contours in $\mathrm{cm}$ ); and (c) barrier layer thickness (shaded in $\mathrm{m}$ ) and CMAP precipitation anomaly (contours in $\mathrm{mm} / \mathrm{day}$ ).

TRITON buoy data over the equatorial Indian Ocean, the latter not included in OIA.

[7] For atmospheric analysis, we use rainfall from CMAP [Xie and Arkin, 1996], surface wind velocity from the QuikSCAT satellite, and tropical cyclone track and intensity from http://weather.unisys.com (best track data).

\section{Westward Propagating Rossby Wave}

[8] The 2006 IOD-related cooling is restricted to east of $85^{\circ} \mathrm{E}$ during boreal summer and fall 2006 (Figure 1a). Hereafter seasons are for the Northern Hemisphere. After the eastern cooling ended in late 2006, most of the STIO displayed warm SST anomalies through spring 2007. The westward propagation of subsurface $(100 \mathrm{~m})$ temperature anomalies (shaded, Figure 1b) from late summer 2006 to winter 2007 is evident in the time-longitude diagram along $10^{\circ} \mathrm{S}$, and is in good agreement with satellite observations of sea surface height anomalies (SSHA, contours). SST anomalies in both our OIA and Reynolds datasets show a westward co-propagation tendency with subsurface temperature anomalies and SSHA anomaly patterns are slightly different between the Reynolds and OIA datasets because of differences in sampling and physical processes for SST and $10 \mathrm{~m}$ temperature.

[9] Figure 2 shows positive subsurface temperature anomalies along $10^{\circ} \mathrm{S}$ from September 2006 to January 2007. The westward and upward propagation of these subsurface temperature anomalies is due to the westward shoaling of the mean thermocline. In September 2006, the maximum subsurface anomalies were found at $90^{\circ} \mathrm{E}$ around $100 \mathrm{~m}$ depth, and in January 2007 they appeared at $\sim 50 \mathrm{~m}$ depth at $65^{\circ} \mathrm{E}$. At $65^{\circ} \mathrm{E}$, the $20^{\circ} \mathrm{C}$ isotherm deepened by some $30 \mathrm{~m}$ during a four-month period from September 2006 to January 2007. In the SWIO where the mean thermocline is shallow, the subsurface warming reaches the surface, leading to strong positive SST anomalies
(Negative subsurface anomalies in the east are associated with the anomalous IOD forcing, that features anomalous easterly winds on the equator).

[10] Thus the westward migration of subsurface temperature anomalies during $2006-07$ is primarily due to the vertical displacement of the thermocline depth associated with the downwelling Rossby wave, which is in turn forced by easterly wind anomalies near the equator in the eastern basin. Easterly wind anomalies were observed in summer 2006 and persisted through winter 2007 in the southeast tropical Indian Ocean, resulting in downward Ekman pumping there (not shown). The forcing and propagation of the 2006-07 Rossby wave event are consistent with the statistical analysis of Xie et al. [2002] but Argo revealed the vertical trapping of subsurface anomalies in the thermocline. Ekman pumping anomalies are weak in the west but the mean upwelling there helps warm SST as the downwelling Rossby wave passes by.

\section{Barrier Layer}

[11] In the Indo-western Pacific warm pool, the isothermal layer is often much deeper than the mixed layer, a separation maintained by low salinity in the latter, say after heavy precipitation. The layer in between is called the barrier layer (BL), isothermal layer depth (ILD), mixed layer depth (MLD) [Godfrey and Lindstrom, 1989]. ILD is defined as the depth at which temperature decreases by $0.5^{\circ} \mathrm{C}$ from SST, and MLD is defined as the depth where density has increased from its surface value by an amount that corresponds to a temperature drop of $0.5^{\circ} \mathrm{C}$. BL forms a barrier to entrainment and turbulent mixing of cold thermocline water into the mixed layer and inhibits the downward mixing of momentum [Vialard and Delecluse, 1998].

[12] Argo observations (Figure 1c) reveal, for the first time, a remarkable westward propagation of BL thickness anomalies during July 2006-April 2007, apparently asso- 

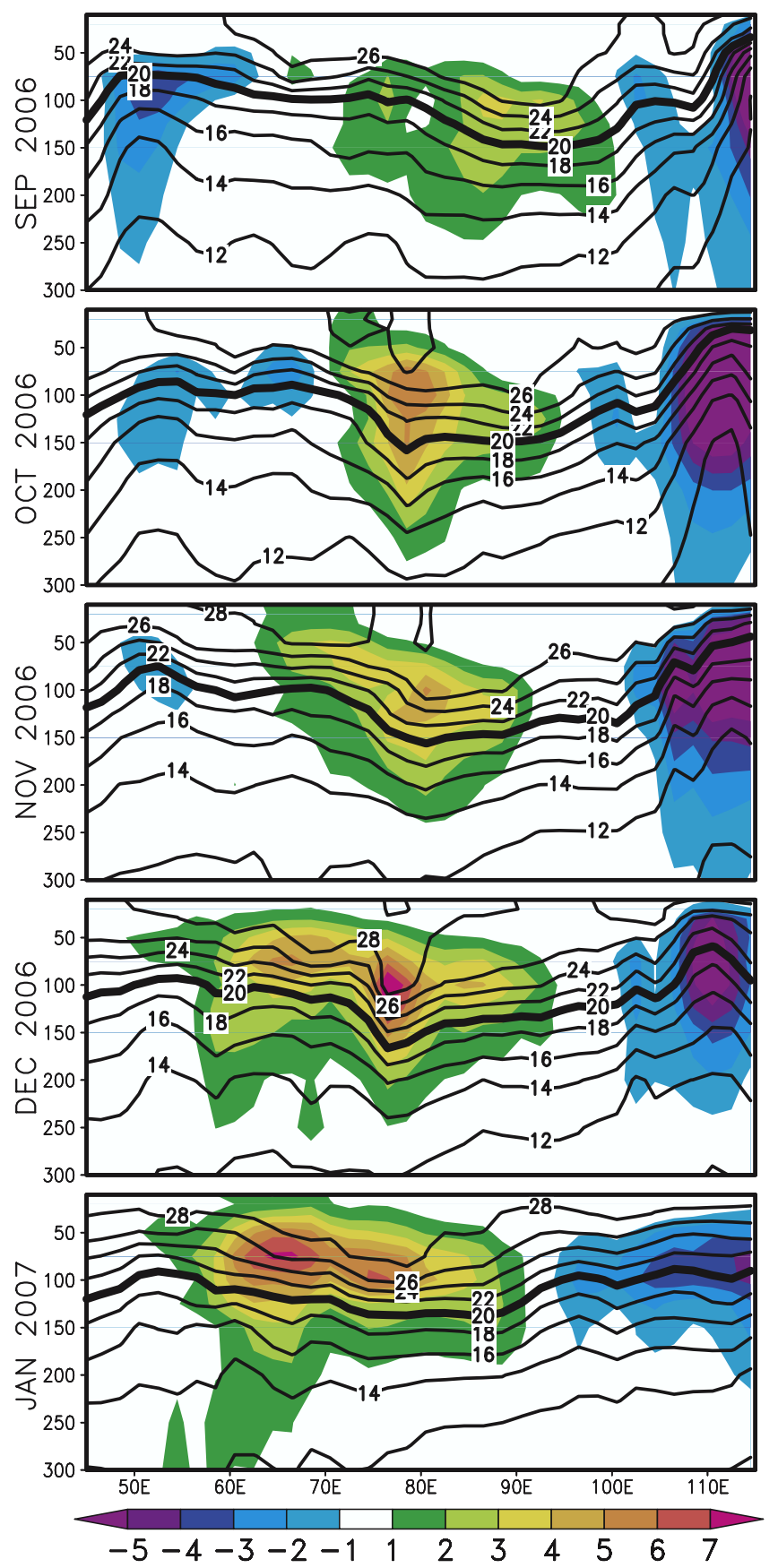

Figure 2. Depth-longitude sections of subsurface temperature anomalies (shaded in ${ }^{\circ} \mathrm{C}$ ), superimposed on mean temperature (the $20^{\circ} \mathrm{C}$ isotherm thickened) at $10^{\circ} \mathrm{S}$ from September 2006 to January 2007.

ciated with the pronounced downwelling Rossby wave. The BL anomalies are on the order of $10 \mathrm{~m}$, up to $20 \mathrm{~m}$ in maximum. The right box indicates the region of negative precipitation anomalies whereas the left box indicates the region of positive precipitation anomalies. The importance of dynamical waves is corroborated by the fact that BL anomalies were weak and did not show coherent propagation during the same period a year before. Shankar et al. [2004] reported similar westward propagation of tempera- ture inversions in the southeastern Arabian Sea associated with a Rossby wave.

[13] Figure 3a shows the time-depth sections of temperature (total field in white contours) and salinity anomalies (shaded) averaged from $75^{\circ} \mathrm{E}$ to $90^{\circ} \mathrm{E}$ and $10^{\circ} \mathrm{S}$ to $5^{\circ} \mathrm{S}$ (hereafter region A) during September 2005 to April 2007. The thick solid line denotes MLD and the dashed line ILD. Salinity anomalies are defined as deviations from background field of the WOA climatology. During September 2005-July 2006 when subsurface anomalies are weak (Figure 1b), region $\mathrm{A}$ is dominated by a semi-annual cycle in the thermocline depth [Yokoi et al., 2008; Hermes and Reason, 2008] and an annual cycle in surface salinity (not shown). The latter is apparently associated with the meridional migration of the Intertropical Convergence Zone (ITCZ).

[14] The downwelling Rossby wave pushed the thermocline downward, nearly eliminating its seasonal shoaling during the second half of 2006 (Figure 3). As a result, ILD increased from $35 \mathrm{~m}$ in October 2005 to $70 \mathrm{~m}$ a year later. The deepened thermocline creates a thick BL during the second half of 2006 (Figure $3 \mathrm{~b}$ ). In the region east of $75^{\circ} \mathrm{E}$, rainfall anomalies are negative (Figure 1c). Indeed, salinity anomalies are positive in the mixed layer, and turn negative in the thermocline. Such salinity anomalies contribute negatively to BL formation. The total salinity averaged from July to December 2006, however, shows a downward gradient (Figure 3b), increasing from 34.65 at $10 \mathrm{~m}$ to $34.95 \mathrm{psu}$ at $130 \mathrm{~m}$. This salinity gradient in the total field was conducive to and allowed BL formation as the downwelling Rossby wave passed by.

[15] From late 2006 to early 2007, precipitation anomalies show a zonal dipole pattern, positive (negative) in the west (east). BL formation differs between the east and west. In the region west of $75^{\circ} \mathrm{E}$, the surface freshening (Figure 4) is caused by positive precipitation (Figure 1c) and possibly by the anomalous westward advection of fresher water from the Indonesian throughflow [Vialard et al., 2009]. In late 2006, both ILD and MLD shallow despite a deepening thermocline. The surface salinity decrease helps the BL formation in the west. This result suggests a possible feedback that could strengthen BL development as follows. The warming along the Rossby wave path increases precipitation [Xie et al., 2002], which provides a surface freshwater source for the BL to form in the west (Figure 1c). The slow Rossby wave propagation sustains the BL for several months. The BL might contribute to increase the surface warming by shielding the surface from the influence of colder thermocline water. Thus the BL development may contribute to the Rossby wave induction of SST warming, an overlooked process conceivably important for the thermocline feedback.

\section{Summary}

[16] We have investigated the 2006-07 downwelling Rossby wave in the tropical SWIO following the cooccurrence of IOD and El Nino. Argo observations show a pronounced up-westward propagation of subsurface warming along the sloping mean thermocline, resulting from a downwelling Rossby wave excited in the $5^{\circ} \mathrm{S}-$ $15^{\circ} \mathrm{S}$ band by equatorial zonal wind anomalies. Our analysis 


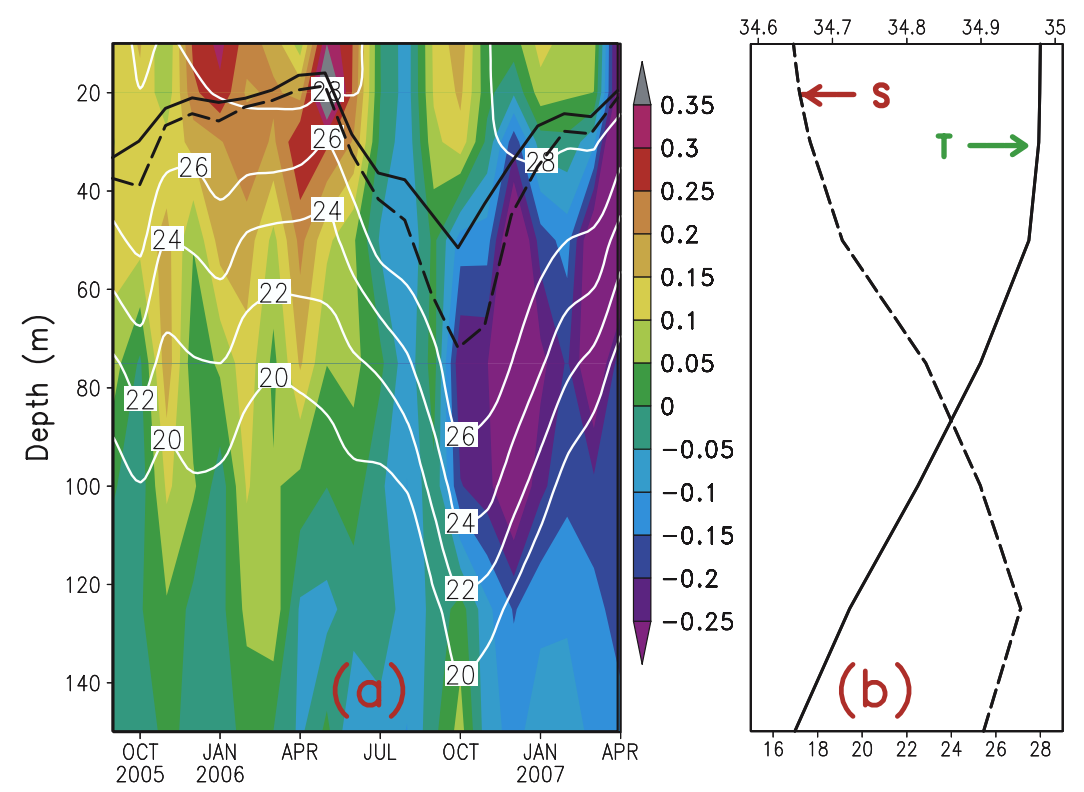

Figure 3. Time-depth sections of OIA mean temperature (white contours; in ${ }^{\circ} \mathrm{C}$ ) and salinity anomaly (shaded; in psu) averaged over the region (a) $75^{\circ} \mathrm{E}-90^{\circ} \mathrm{E}$ and $10^{\circ} \mathrm{S}-5^{\circ} \mathrm{S}$ (b) mean salinity (dashed line) and temperature (continues line) averaged from July to December 2006. The thick solid line in Figure 3a shows MLD and the dashed line ILD.

reveals a robust westward propagation of BL thickness, adding a new aspect to the dynamical Rossby wave forming. The downwelling Rossby wave helps form a BL by deepening the isothermal layer and increasing precipitation. We suggest a positive feedback between SST warming and BL development as follows. The warming along the Rossby wave path increases precipitation [Xie et al., 2002], for a change in freshwater flux favorable for BL formation in the region west of $75^{\circ} \mathrm{E}$. The $\mathrm{BL}$ may strengthen the surface warming by shielding the surface from the influence of colder thermocline water in the tropical SWIO. Further studies are necessary to quantify this mechanism.
[17] The Rossby wave-induced surface warming maintains active convection and a cyclonic circulation in surface wind over the SWIO (not shown). Seven tropical cyclones (TCs) formed in the South Indian Ocean during December 2006 to April 2007, slightly more than the climatological mean of five (standard deviation is 3.6). Most of these TCs formed just south of the SWIO thermocline ridge and traveled southwest towards Madagascar. Large heat content in the downwelling Rossby wave may have contributed to the active TC season of 2006-07, as suggested from empirical studies [Xie et al., 2002]. Atmosphere-ocean coupled model studies are required to investigate the role

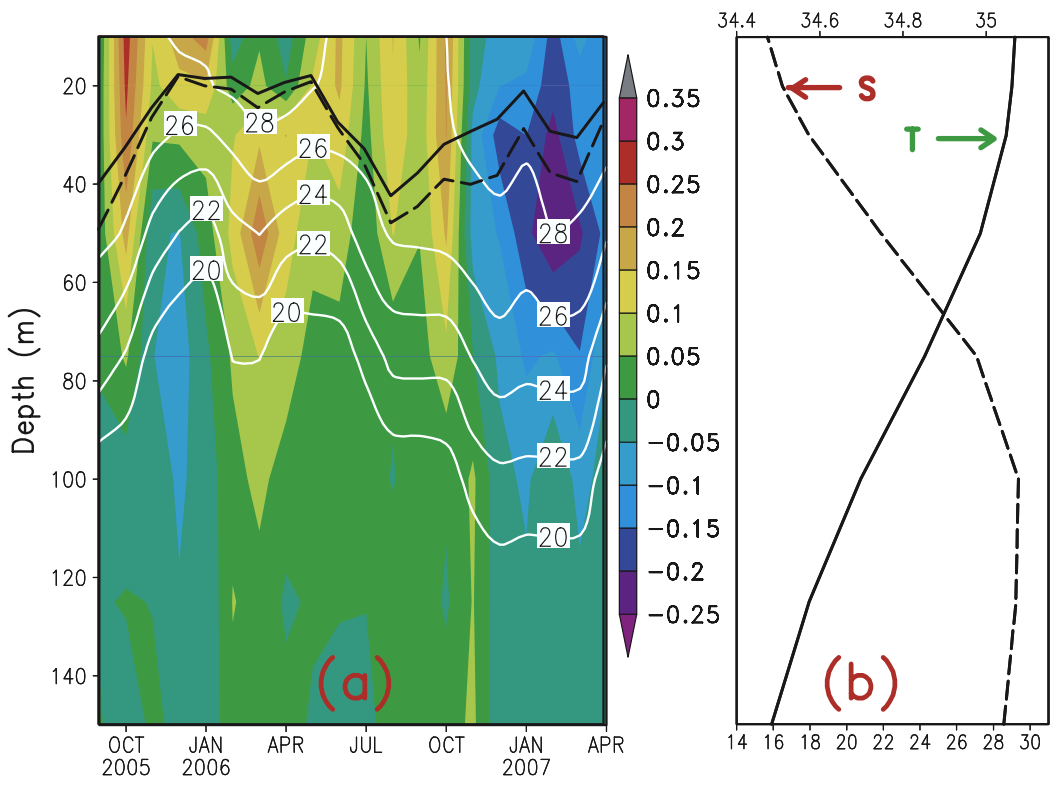

Figure 4. Same as Figure 3 except over the region $55^{\circ} \mathrm{E}-75^{\circ} \mathrm{E}$ and $10^{\circ} \mathrm{S}-5^{\circ} \mathrm{S}$. 
of heat content on TC generation and intensification over this region.

[18] Acknowledgments. The authors wish to thank INCOIS, Hyderabad for financial support, IITM Director for encouragement, J. Vialard for comments, and A. Barth for the OIA code. Argo is a pilot program of Global Ocean Observing System and its freely available data made this study possible. This study is partly supported by JAMSTEC and NASA. Figures were prepared using GrADS. IPRC publication \# 582.

\section{References}

Annamalai, H., P. Liu, and S.-P. Xie (2005), Southwest Indian Ocean SST variability: Its local effect and remote influence on Asian monsoons, J. Clim., 18, 4150-4167.

Barth, A., A. Alvera-Azcárate, J. M. Beckers, M. Rixen, and L. Vandenbulcke (2007), Multigrid state vector for data assimilation in a two-way nested model of the Ligurian Sea, J. Mar. Syst., 64, 41-59.

Chowdary, J. S., and C. Gnanaseelan (2007), Basin wide warming of the Indian Ocean during El Niño and Indian Ocean Dipole years, Int. J. Climatol., 27, 1421-1438.

Duvel, J. P., R. Roca, and J. Vialard (2004), Ocean mixed layer temperature variations induced by intraseasonal convective perturbations over the Indian Ocean, J. Atmos. Sci., 61, 1004-1023.

Godfrey, J. S., and E. J. Lindstrom (1989), The heat budget of the equatorial western Pacific surface mixed layer, J. Geophys. Res., 94, 8007-8017.

Gould, J., et al. (2004), Argo profiling floats bring new era of in situ ocean observations, Eos Trans. AGU, 85(19), doi:10.1029/2004EO190002.

Hermes, J. C., and C. J. C. Reason (2008), Annual cycle of the South Indian Ocean (Seychelles-Chagos) thermocline ridge in a regional ocean model, J. Geophys. Res., 113, C04035, doi:10.1029/2007JC004363.

Huang, B., and J. L. Kinter III (2002), Interannual variability in the tropical Indian Ocean, J. Geophys. Res., 107(C11), 3199, doi:10.1029/ 2001JC001278

Izumo, T., C. de Boyer Montegut, J.-J. Luo, S. K. Behera, S. Masson, and T. Yamagata (2008), The role of the western Arabian Sea upwelling in Indian monsoon rainfall variability, J. Clim., 21, 5603-5623.

Masumoto, Y., and G. Meyers (1998), Forced Rossby waves in the southern tropical Indian Ocean, J. Geophys. Res., 103, 27,589-27,602.

Reason, C. J. C., and H. Mulenga (1999), Relationships between South African rainfall and SST anomalies in the southwest Indian Ocean, Int. J. Climatol., 15, 1651-1673.

Reynolds, R. W., N. A. Rayner, T. M. Smith, D. C. Stokes, and W. Wang (2002), An improved in situ and satellite SST analysis for climate, J. Clim., 15, 1609-1625.
Saji, N. H., B. N. Goswami, P. N. Vinayachandran, and T. Yamagata (1999), A dipole mode in the tropical Indian Ocean, Nature, 401, $360-363$

Schott, F. A., S.-P. Xie, and J. P. McCreary Jr. (2009), Indian Ocean circulation and climate variability, Rev. Geophys., 47, RG1002, doi:10.1029/ 2007RG000245.

Shankar, D., V. V. Gopalakrishna, S. S. C. Shenoi, F. Durand, S. R. Shetye, C. K. Rajan, Z. Johnson, N. Araligidad, and G. S. Michael (2004), Observational evidence for westward propagation of temperature inversions in the southeastern Arabian Sea, Geophys. Res. Lett., 31, L08305, doi:10.1029/2004GL019652.

Vecchi, G. A., and D. E. Harrison (2004), Interannual Indian rainfall variability and Indian Ocean sea surface temperature anomalies, in Earth Climate: The Ocean-Atmosphere Interaction, Geophys. Monogr. Ser., vol. 147, edited by C. Wang, S.-P. Xie, and J. A. Carton, pp. 247260, AGU, Washington, D. C.

Vialard, J., and P. Delecluse (1998), An OGCM study for the TOGA decade. Part II: Barrier layer formation and variability, J. Phys. Oceanogr., 28, 1089-1106.

Vialard, J., et al. (2009), Cirene: Air-sea interactions in the SeychellesChagos thermocline ridge region, Bull. Am. Meteorol. Soc., in press.

Vinayachandran, P. N., J. Kurian, and C. P. Neema (2007), Indian Ocean response to anomalous conditions in 2006, Geophys. Res. Lett., 34, L15602, doi:10.1029/2007GL030194.

Xie, P., and P. A. Arkin (1996), Analyses of global monthly precipitation using gauge observations, satellite estimates, and numerical model predictions, J. Clim., 9, 840-858.

Xie, S.-P., H. Annamalai, F. A. Schott, and J. P. McCreary Jr. (2002), Structure and mechanisms of South Indian Ocean climate variability, J. Clim., 15, 864-878.

Yokoi, T., T. Tozuka, and T. Yamagata (2008), Seasonal variation of the Seychelles dome, J. Clim., 21, 3740-3754.

Yu, W., B. Xiang, L. Liu, and N. Liu (2005), Understanding the origins of interannual thermocline variations in the tropical Indian Ocean, Geophys. Res. Lett., 32, L24706, doi:10.1029/2005GL024327.

J. S. Chowdary and C. Gnanaseelan, Theoretical Studies Division, Indian Institute of Tropical Meteorology, Dr. Homibhaba Road, Pune, Maharashtra 411008, India. (seelan@tropmet.res.in)

S. P. Xie, International Pacific Research Center and Department of Meteorology, SOEST, University of Hawaii, 1680 East West Road, Honolulu, HI 96822, USA. 